\title{
Lampion Hias Bernilai Estetika untuk Meningkatkan Kreativitas Karang Taruna
}

\author{
${ }^{1 *}$ Fenny Rochbeind, ${ }^{2}$ Sumarwahyudi, ${ }^{3}$ Lisa Sidyawati \\ Universitas Negeri Malang; Jalan Semarang 5 Malang \\ *Corresponding author: fennroch@yahoo.com
}

\begin{abstract}
Abstrak
Kegiatan pengabdian ini diperuntukkan bagi karang taruna dikawasan wisata Kampung Heritage Kajoetangan Kota Malang. Bertujuan untuk meningkatkan kreativitas peserta, potensi diri dibidang kreatif, menambah pengetahuan dan pengalaman artistik melalui pembuatan lampion hias. Kebutuhan akan pencahayaan dilokasi kawasan wisata bukan hanya untuk keindahan tetapi memeriahkan tampilan permukiman khususnya di malam hari. Pembekalan keterampilan bagi karang taruna sangat diharapkan dan dipastikan untuk kurun waktu tertentu, secara berkesinambungan kawasan ini menjadi sentra industri kreatif berbasis budaya lokal yang memiliki nilai ekonomis yang cukup tinggi. Masalahnya aktivitas karang taruna sangat kurang dibidang kreatif, belum memiliki kompetensi mengembangkan potensi kreatif berolah seni rupa dan kerajinan untuk memperindah lingkungan yang menjadi objek kunjungan wisata sehingga perlu dilatih. Metode yang digunakan diantaranya pengayaan, metode pembelajaran, metode partisipatif, dan metode evaluasi untuk mengetahui perubahan pengetahuan, keterampilan, dan wawasan/perilaku khalayak sasaran. Manfaat dari kegiatan pelatihan penting untuk meningkatkan kreativitas peserta, mampu berwirausaha, memiliki motivasi tinggi untuk mengembangkan potensi diri, dan menggunakan keterampilan yang dimiliki untuk memperindah, memelihara, dan melestarikan lingkungan kawasan kampung wisata Kajoetangan.
\end{abstract}

Kata kunci-lampion hias, kreativitas, Kampung Heritage Kajoetangan Malang.

\begin{abstract}
Community service activity is for young people in the tourism area of Kajoetangan Heritage Village, Malang. Aiming to increase participant's creativity, self potential in the creative field, increase knowledge and artistic experience through making decorative lanterns. The need for lighting in the tourist area is not just for beauty but enliven the appearance of settlements, especially at night. Provision of skills for youth is highly expected and ensured for a certain period of time, this area will continuously become a center for creative industries based on local culture that has a high economic value. The problem is that the activities of the youth group are very lacking in the creative field, and do not yet have the competence to develop the creative potential to work in the arts and crafts to beautify the environment that is the object of a tourist visit so they need to be trained. The methods used include enrichment, learning methods, participatory methods, and evaluation methods to determine changes in knowledge, skills, and insights/behavior of the target audience. The benefits of the training activities are important to increase the creativity of the participants, being able to become entrepreneurs, have high motivation to develop their potential, and use their skills to beautify, maintain, and preserve the environment of the Kajoetangan tourist village.
\end{abstract}

Keywords - ornamental lanterns, creativity, Kampung Heritage Kajoetangan Malang

\section{PENDAHULUAN}

$\mathrm{K}$ ampung Heritage Kajoetangan terletak di Jl. Jend. Basuki Rachmat, Kelurahan Kauman, Kecamatan Klojen, Kota Malang, diresmikan pada bulan April 2018 hingga kini semakin ramai dikunjungi wisatawan. Di kawasan ini tercatat kurang lebih 20 rumah yang ditetapkan sebagai warisan budaya, demikian juga citra budaya Jawa cukup dilestarikan seperti taman dolanan yang menawarkan permainan anak-anak jaman dulu/jadul, seperti Gobak Sodor dan Congklak.

Kegiatan pelatihan ini dilakukan sebagai upaya pengembangan kreativitas yang ditujukan bagi karang taruna karena nantinya berdampak pada usaha rumahan/home industry yang kini mulai berkembang di kawasan ini dan mendapat perhatian pemerintah seperti Indonesian Marketing Association Chapter 
Malang akhirnya tampil untuk menggagas program bernama Save Malang Heritage. Kawisata Kampung Heritage Kajoetangan juga memiliki manajemen yang tertata dan dikelola dengan baik atas swadaya masyarakat.

Layaknya sebuah objek wisata pasti diharapkan ada perkembangan seiring waktu. Perkembangan terjadi secara bertahap dengan kehadiran tim pengabdian yang melaksanakan pelatihan membuat lampion hias sebagai upaya penerangan layaknya kampung wisata yang sangat dibutuhkan saat ini. Selain itu warga berharap pengunjung bukan hanya berkunjung hingga sore hari tetapi malam hari juga ramai pengunjung. Pelatihan bermanfaat untuk membekali karang taruna dari 4 RT dengan keterampilan membuat lampion hias bernilai estetika dan pengembangannya dikemudian hari.

Lingkungan sangat berpengaruh pada upaya pengembangan potensi kreatif khususnya di Kampung Kajoetangan yang dibina dan dilatih agar mampu berpikir dan bertindak kreatif. Menurut Munandar (1999), kreativitas adalah hasil proses interaksi antara individu dan lingkungannya. Seseorang dapat mempengaruhi dan dipengaruhi oleh lingkungan di mana mereka berada.

Lingkungan seperti Kampung Heritage Kajoetangan selayaknya didukung untuk menciptakan suasana meriah yang menampilkan perwajahan kampung tematik yang diwarnai berbagai aktivitas berkesenian, karena merupakan kawasan yang sangat potensial dibidang wisata Kota Malang. Dibandingkan dengan 16 kampung tematik lainnya di Malang, Kampung Heritage Kajoetangan perlu lebih menonjol dalam tampilannya agar makin cantik dan menarik perhatian pengunjung. Kampung warna-warni Jodipan nampak lebih memukau wisatawan dengan kemeriahannya, baik dari warna maupun ornamen yang menghiasi disepanjang jalan. Demikian juga dengan kampung tematik lainnya di wilayah Malang memiliki karakteristik yang berbeda kini bersaing menghias kampungnya. Kampung Heritage Kajoetangan merupakan 1 diantara 5 Kampung Tematik Terinstagenic di Indonesia harus memiliki daya saing khususnya dari tampilan fisik kampung dan sumber daya manusia yang potensial untuk dikembangkan agar berhasil guna mempromosikan kampungnya dan tentunya Kota Malang.

Sudah selayaknya kaum muda sebagai penerus memiliki kesadaran dan kepedulian dengan melahirkan ide-ide kreatif terhadap lingkungannya. Selanjutnya berproses kreatif untuk memperindah lingkungan sekitarnya agar lebih menarik perhatian pengunjung dan mendatangkan pemasukan yang menguntungkan warga setempat.
Masalahnya, (1) aktivitas anggota karang taruna di Kampung Heritage Kajoetangan sangat kurang dibidang kreatif, sebab belum memiliki kompetensi mengembangkan potensi kreatif berolah seni masyarakat khususnya kaum muda untuk memperindah lingkungan kawasan wisata Kampung Heritage Kajoetangan, (2) belum ada kesadaran akan potensi diri kaum muda yang terlibat dalam kelompok karang taruna untuk peduli pada kebutuhan lingkungan melalui sumbang gagasan atau aksi kreatif yang dapat memperindah kampung tematik secara berkala sesuai kebutuhan sebuah kawasan wisata, (3) pencahayaan di tempat kunjungan wisata di kawasan Kampung Heritage Kajoetangan sangat diperlukan, sehingga dibutuhkan kerjasama dengan berbagai pihak yang memiliki kepedulian.

Artinya kelompok karang taruna ini sangat tepat dibekali dengan keterampilan melalui pelatihan membuat lampion hias, sesuai kebutuhan akan penerangan lingkungan.

Proses pembuatan lampion cukup sederhana, dan mudah dikerjakan sehingga tidak sulit untuk dikuasai, baik dari segi teknik maupun medium yang digunakan tahan terhadap cuaca. Filosofinya, cahaya lampion menjadi simbol pengharapan atas datangnya keberuntungan, rezeki, dan kebahagiaan.

Untuk kawasan wisata, bentuk pencahayaan/penerangan yang maksimal merupakan suatu kemeriahan, cukup menarik perhatian pengunjung, karena selain memberi rasa aman bagi pengunjung, juga bernilai estetis. Nilai estetis menurut Kartika (2004) terdapat pada garis, bentuk, warna, dalam seni rupa. Lampion merupakan karya seni rupa yang tampilannya dapat mewakili budaya suatu daerah, bukan hanya bentuk tetapi dekorasi yang memperindah keseluruhan wujud fisiknya.

Lampion didekorasi dengan motif geometris dan motif flora bertema budaya yang berciri khas lokal Malang dikreasikan sebagai bentuk pelestarian budaya yang bernilai estetis dan dapat mengeedukasi masyarakat. Bahkan dikemudian hari peserta pelatihan dapat mengembangkan keterampilan lanjutan dengan menerapkan teknik menghias lampion ke ragam medium dan kebutuhan terkait produksi yang bernilai jual.

Setelah ditelusuri ada beberapa penulisan ilmiah tentang pembuatan lampion hias dengan medium berbeda dari kertas, rotan, benang sebagai elemen estetika interior maupun ekstrior yang bernilai jual tinggi.

Diharapkan lampion hias yang diciptakan dan dikreasikan dengan motif tradisi lokal Malang selain untuk penerangan yang sangat dibutuhkan oleh sebuah kampung wisata, juga akan 
memperindah dan menyemarakkan tampilan Kampung Wisata Kajoetangan.

Oleh karena itu bimbingan dan pelatihan cara membuat lampion hias bernilai estetis sesuai tahapannya hingga display di lokasi, merupakan solusi atas kebutuhan sebuah tempat wisata agar terkesan unik, artistik, estetik, dan menarik perhatian khususnya di malam hari sangat diperlukan untuk membekali kelompok karang taruna Kampoeng Haritage Kajoetangan.

\section{METODE}

Metode yang digunakan agar tercapai tujuan kegiatan pengabdian ini adalah, Metode Pengayaan untuk menambah pengetahuan khususnya pembuatan lampion hias bernilai estetis, khususnya terkait pengetahuan alat dan bahan membuat lampion dan mendekorasinya, proses berupa tahapan sesuai prosedur hingga finishing dan display lampion.

Metode pembelajaran yang meliputi metode ceramah, diskusi, demonstrasi, dan drill, serta metode partisipatif dan evaluasi. Dalam hal ini peserta membutuhkan pendampingan, bimbingan langsung dan dievaluasi tiap langkah kerja dari perancangan, pelaksanaan, hingga tahap akhir finishing dan display. Adapun khalayak dan strategi pelatihan ini diikuti oleh kelompok karang taruna Kampung Heritage Kajoetangan Kelurahan Kauman, RT03, 04,05, dan 06 yang masih relatif muda antara 16 sampai dengan 25 tahun.

\section{HASIL DAN PEMBAHASAN}

Pada pembahasan hasil pengabdian ini dideskripsikan tahapan mulai dari persiapan hingga pelaksanaan kegiatan pelatihan membuat lampion hias untuk meningkatkan kreatifitas karang taruna dikampung Heritage Kajoetangan Malang. Pada tahap persiapan tim pengabdi mengadakan pertemuan dengan manajemen setempat untuk mendiskusikan alur kegiatan, jadwal, dan peserta yang akan dilatih pada saat pengabdian berlangsung. Peserta yang terdaftar untuk ikut pelatihan merupakan anggota karang taruna dari 4 RT yang antusias mewakili RT masing-masing berjumlah lima orang pilihan.

Tahap pelaksanaan dimulai dengan penyampaian materi membuat lampion hias bernilai estetika oleh tim pengabdi mengenai pengenalan alat dan bahan, teknik, dan proses pembuatan lampion hias kepada para peserta.

Materi lampion hias meliputi, mendesain bentuk lampion, cara membuat lampion, menghias lampion dengan motif tertentu khas Malang, bisa ragam hias yang diambil dari lingkungan sekitar Kota Malang atau icon Malang. Ragam hias ini didesain di kertas berbentuk stilasi benda yang ada di alam, seperti bentuk tumbuh-tumbuhan maupun ikon malang seperti Tugu Malang. Selanjutnya sketsa di atas kertas tadi dipindahkan kepermukaan kain sebagai bahan dasar pembuatan lampion.

Selain materi ragam hias, peserta diberi materi mengenai pengenalan alat dan bahan serta teknik perakitan lampion sesuai desain pilihan dan teknik pewarnaan. Setelah itu peserta diberi kesempatan tanya jawab dengan nara sumber. Antusiasme peserta nampak pada banyaknya pertanyaan yang disampaikan, dan nara sumber memaksimalkan jawaban agar dipahami oleh peserta. Setelah penyampaian materi selesai langsung dilanjutkan dengan merancang bentuk lampion hias.

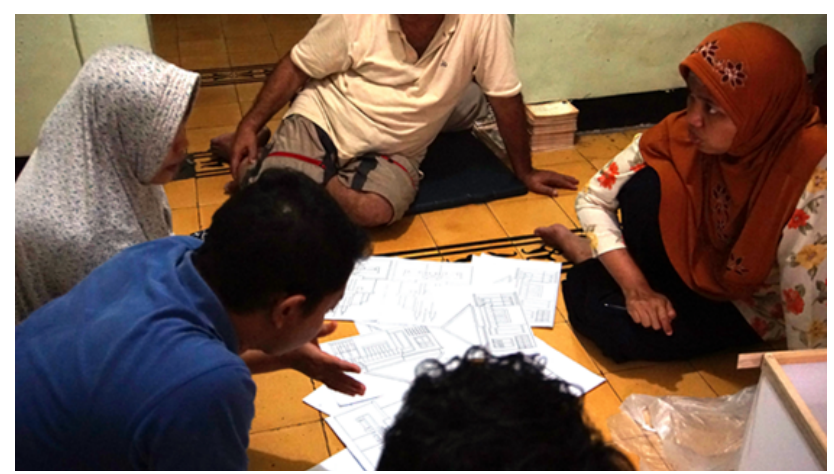

Gambar 1. Proses Merancang Desain Lampion

Setelah bentuk lampion yang akan diwujudkan disepakati sesuai desain terpilih, dilanjutkan dengan pengenalan alat dan bahan serta tahapan kerja membuat lampion hias. Ukuran lampion ditetapkan $20 \times 35 \mathrm{~cm}$ berbentuk persegi empat. Alat yang disiapkan seperti palu, gergaji kayu, paku, staples, amplas, sedangkan bahan utama kayu, tripleks, kain santung, lem kayu, dan cat akrilik.

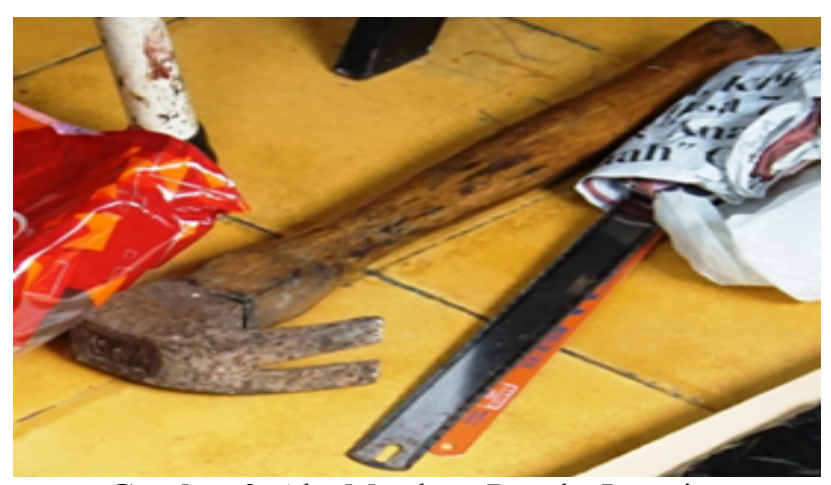

Gambar 2. Alat Membuat Rangka Lampion 


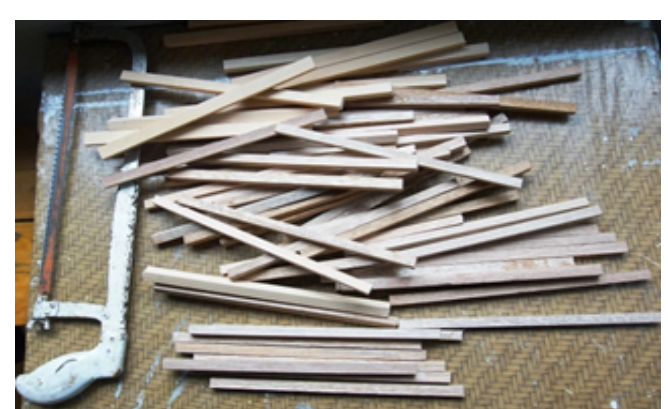

Gambar 3. Bahan Kayu untuk Rangka Lampion

Aktivitas berikutnya adalah memotong dan mewarnai tripleks sebagai lis pinggir yang menjepit kain dan kayu. Tripleks yang dipotong dengan menggunakan pisau/cutter lebarnya $3 \mathrm{~cm}$ dan dicat dengan warna hitam menggunakan cat akrilik.

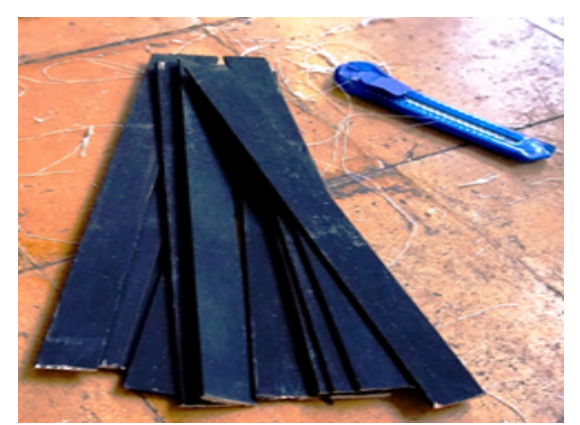

Gambar 4. Tripleks diwarnai dan dipotong

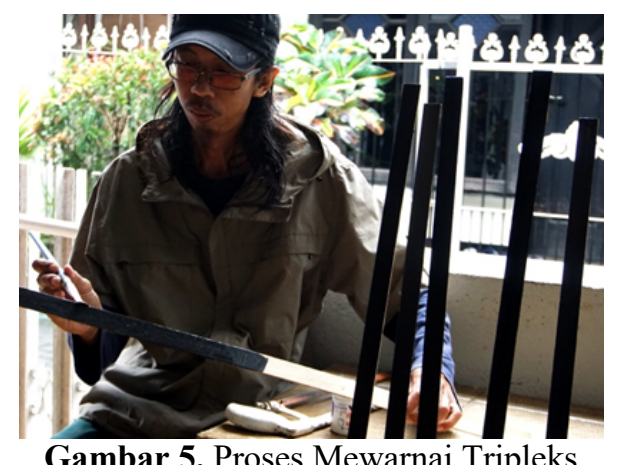

Tahap berikutnya adalah menyambung kayu yang telah dipotong panjang kali lebar dengan cara dipaku untuk mewujudkan rangka lampion.

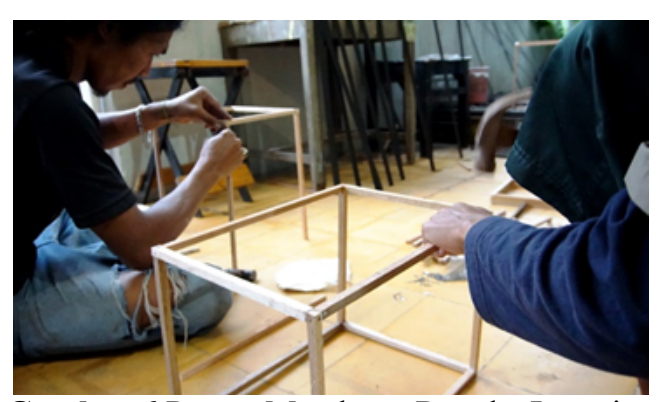

Gambar 6 Proses Membuat Rangka Lampion
Setelah rangka lampion jadi, lalu menyiapkan kain putih (kain santung). Seluruh permukaan rangka lampion khususnya sisi bagian luar dilumuri dengan lem lalu kain ditempelkan, setelah kain menempel, lis dari tripleks dipasang untuk memperkuat rekatan kain dengan kayu.

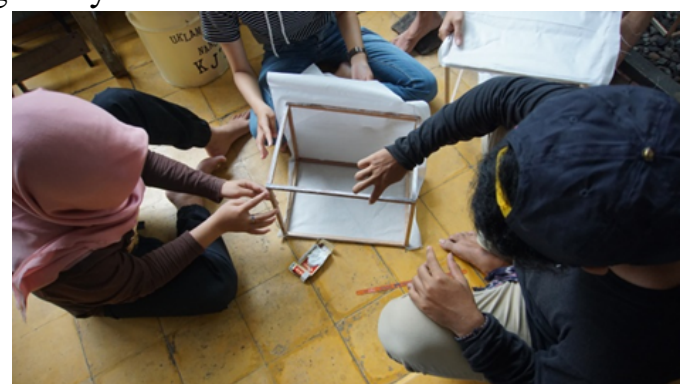

Gambar 7. Merekatkan Kain di Rangka Lampion

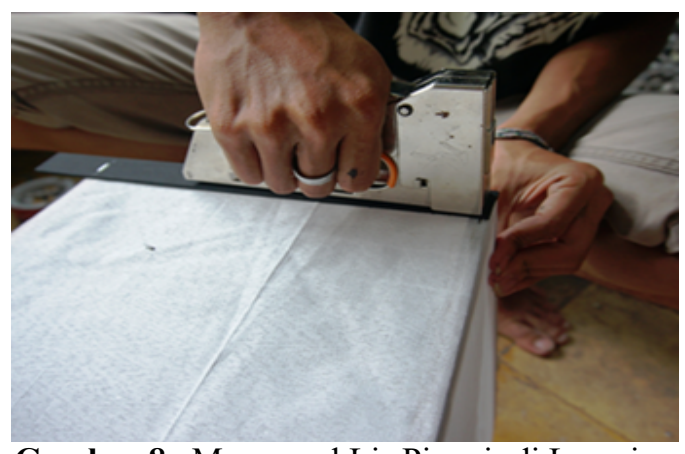

Gambar 8. Menempel Lis Pinggir di Lampion

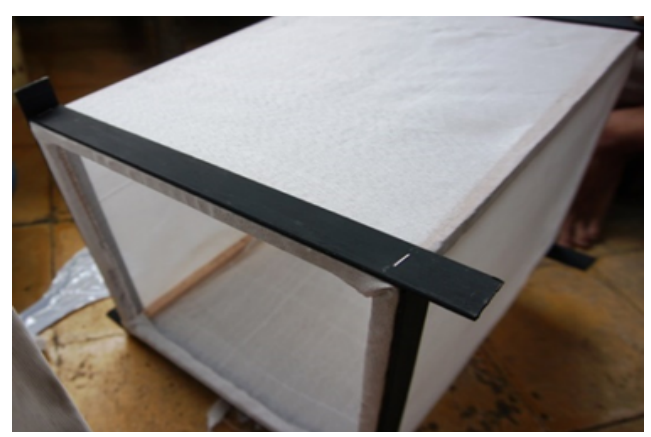

Gambar 9. Lis Pinggir Terpasang di Lampion

Setelah lampion selesai dikerjakan, dilanjutkan dengan menghias lampion dengan dekorasi motif ragam hias flora yang distilasi sesuai rancangan desain peserta yang telah dibuat sebelumnya. Selain itu ada peserta yang terispirasi pada ikon tugu Malang. Proses pengerjaan lampion perlu dipantau oleh tim pengabdi disetiap tahapan pengerjaannya agar tidak ada kesalahan atau kekeliruan dalam proses pengerjaan dan penyelesaiannya. 


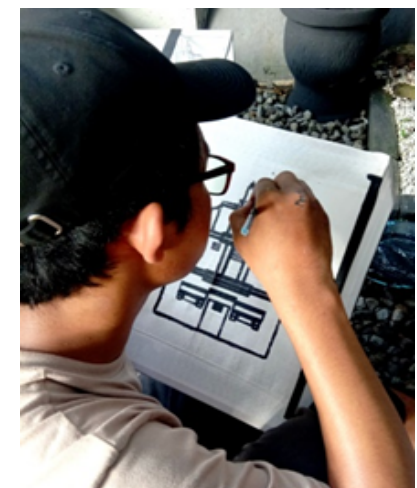

Gambar 10. Proses Mendekorasi

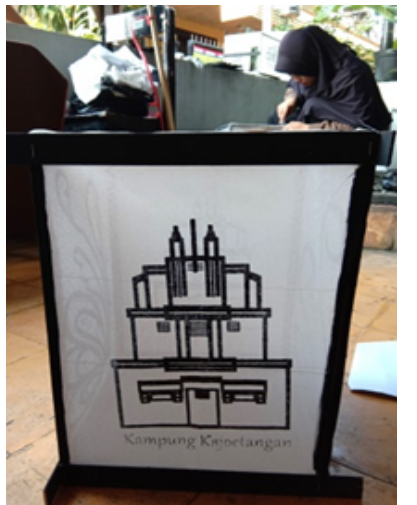

Gambar 11. Hasil Pendekorasian

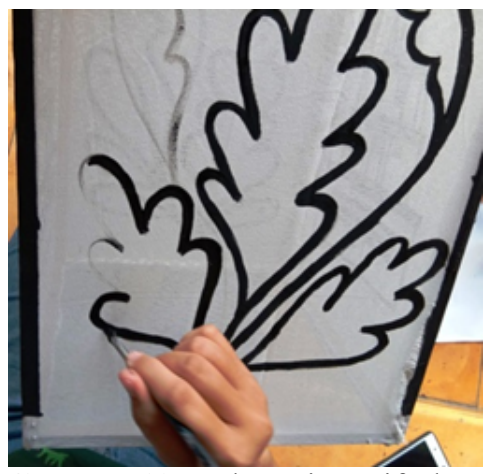

Gambar 12. Dekorasi Motif Flora

Saat lampion mencapai tahap $80 \%$ pengerjaan khususnya saat mendekorasi lampion, kemampuan menggambar ragam hias peserta berbeda-beda. Jadi perlu sedikit kehati-hatian dalam menarik garis dan pewarnaan, sehingga latihan menggores juga diperlukan. Sementara yang dilatihkan adalah bentukbentuk sederhana berupa stilasi motif tumbuhan/flora yang tidak rumit.

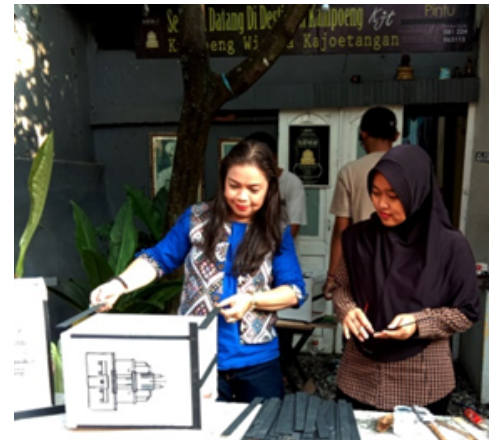

Gambar 13. Kegiatan Pemantauan

Usai mendekorasi lampion dengan motif hias dilanjutkan dengan pemasangan lampu (ball lamp 5 watt). Bahan Lampu dilengkapi viting dan kabel. Setelah diuji cobakan dipasang pada lampion

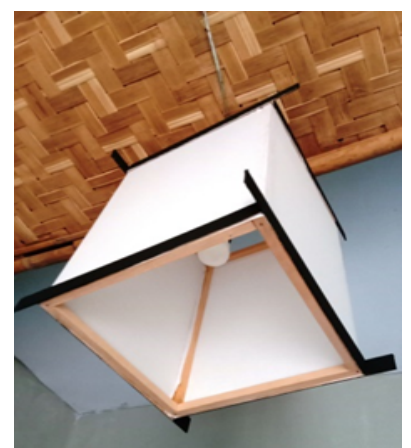

Gambar 14. Pemasangan Lampu di Lampion

Jumlah lampion yang dikerjakan ada 20 buah lampion yang siap dipasang dibeberapa titik lokasi yang telah disepakati dengan warga setempat khususnya di sekitar gang VI kampung Wisata Heritage Kajoetangan.

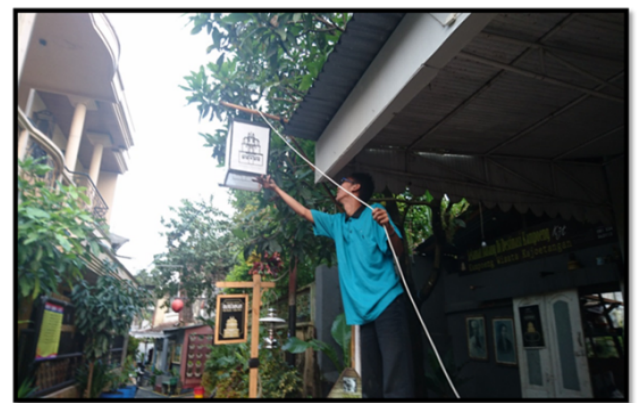

Gambar 15. Display Lampion di Lingkungan

Adapun pembahasan keberhasilan dalam sebuah kegiatan pelatihan ini dapat diukur melalui evaluasi program yang dijalankan sangat bermanfaat, evaluasi proses kegiatan menunjukkan peserta cukup antusias, dan evaluasi hasil dari kegiatan itu sendiri cukup memuaskan.

Dalam proses kegiatan keaktifan peserta dinilai telah menunjukkan kesungguhan dan antusiasme 
dalam pelatihan, baik keaktifan bertanya, kehadiran, ketekunan, dan ketepatan waktu penyelesaian.

Tingkat keterampilan para peserta dapat diukur melalui pengamatan (observasi) di lapangan saat praktek membuat lampion sedang berlangsung khususnya penilaian terhadap kecepatan, ketepatan, dan kerapian. Tolak ukur tingkat keterampilan dalam pelatihan ini meliputi ketepatan teknik dalam perancangan/mendesain, membuat rangka hingga wujud utuh lampion, mengaplikasi desain ragam hias kepermukaan kain/lampion, pemasangan lampu, finishing, hingga display lampion di lokasi yang disepakati.

Adapun fator pendukung saat pelaksanaan diantaranya; 1) peserta pelatihan siap berkomitmen mengikuti keseluruhan proses pelatihan tahap demi tahap dari awal hingga akhir kegiatan pelatihan, 2) terpenuhinya sarana dan kebutuhan dilokasi berkat kerjasama dengan mitra dalam hal ini manajemen Kampung Heritage Kajoetangan, 3) pihak Fakultas Sastra UM dan jurusan memberi dukungan fasilitas serta motivasi bagi kelancaran pelaksanaan pelatihan. Sedangkan faktor penghambat kegiatan dintaranya: 1) tingkat keterampilan peserta berbeda-beda. Ada yang kurang, sedang, dan mahir, sehingga yang kurang mampu perlu ekstra perhatian dalam pendampingan dan penggunaan waktu yang lebih dibanding peserta lainnya, 2) keterbatasan waktu pelatihan yang hanya dua hari saja, sedangkan yang dibutuhkan untuk memaksimalkan hasil yang sempurna seharusnya lebih.

Keberhasilan kegiatan ini dapat diukur dari beberapa indikator diantaranya adalah:

a. Kemampuan mengumpulkan ide/gagasan membuat desain, baik desain lampion maupun ragam hias, serat pewarnaan.

b. Kemampuan secara teknis pengerjaan mewujudkan lampion, teknik menggambar, pemasangan lampu, dan display lampion hias.

Hasil akhir berupa lampion hias bernilai estetik dapat dinilai berhasil diwujudkan oleh para peserta pelatihan walaupun tidak $100 \%$ bagus. Hal ini dapat dinilai dari kerapihan kerja dan desain ragam hias yang dihasilkan sangat sederhana. Para peserta pelatihan telah berusaha membuat lampion hias sebaik mungkin, kekurangan yang nampak bisa dimaklumi mengingat peserta belum pernah mendapatkan pengetahuan maupun pelatihan sebelumnya.

\section{SIMPULAN}

Tujuan pelatihan untuk membekali warga dalam hal ini karang taruna dengan keterampilan berolah seni, sehingga muncul rasa kesadaran, kepedulian, untuk mengembangkan potensi diri masing-masing sehingga termotivasi untuk berkreasi dan berinovasi yang berguna bagi masyarakat dan lingkungannya. Pelatihan membuat lampion hias ini hanyalah satu dari sekian banyak kegiatan untuk melatih keterampilan kaum muda kampung yang tergabung di karang taruna dan merupakan pemicu atau pemantik kreativitas yang akan terus dikembangkan seiring perkembangan zaman. Tujuan utama dari pembuatan lampion hias bernilai estetika adalah agar peserta memiliki pemahaman tentang alat dan bahan untuk membuat dan mendekorasi lampion hias berbasis budaya lokal Malang, memahami proses kerja sesuai prosedur atau tahapan dari proses mendesain, membuat rangka, mendekorasi (menggambar ragam hias dipermukaan lampion), finishing, hingga display. Manfaat kegiatan pelatihan akhirnya dapat dirasakan oleh peserta selain mendapat tambahan pengetahuan, pengalaman kerja, kemampuan bekerja sama, menghargai pendapat orang lain terkait ide/gagasan yang disampaikan, pengalaman berolah seni (merancang, menggambar, dan mewarnai), peningkatan kualitas diri, meningkatkan rasa percaya diri atas kualitas yang dimiliki sehingga akan terus mengembangkan diri masing-masing. Yang terpenting dari hasil pelatihan ini akan memicu kreatifitas peserta untuk terus berkreasi menghasilkan produk seni yang memiliki nilai pasar demi mempertahankan citraan Kampung tematik yang turut mempromosikan Malang sebagai kota wisata.

\section{DAFTAR RUJUKAN}

Hari Poerwanto. (2000). Kebudayaan dan Lingkungan. Yogyakarta: Pelajar Pustaka.

Indrawati, Lilik. (2009). Nirmana (Organisasi Visual). Malang: Universitas Negeri Malang

Kartika, Sony Dharsono. (2007). Estetika. Bandung: Rekayasa Since

Munandar, S. C, Utami.

Kreativitas\& Keberbakatan,Strategi

Mewujudkan Potensi Kreatif dan Bakat. Jakarta: Penerbit PT Gramedia Pustaka Utama

Sahman, H. (1993). Mengenal Dunia Seni Rupa: Tentang Seni, Karya Seni, Aktifitas Kreatif, Apresiasi, Kritik, dan Estetika. Semarang: IKIP Semarang Press

Sunaryo, Aryo. (2009). Ornamen Nusantara-Kajian Khusus tentang Ornamen Indonesia. Semarang: Dahara Prize

Sanyoto, S. E. (2005). Dasar-dasar Tata Rupa dan Desain (Nirmana). Yogyakarta: Arti Bumi Intaran

Soekiman, D. (2000). Kebudayaan Indies dan Kehidupan Masyarakat Pendukung di jawa 
(Abad XVIII-Medio Abad XX). Yogyakarta: Yayasan Bentara Budaya

Lugyana. (2012). Lampion, (online) luqyanaf.blogspot.com, diakses 14 Agustus 2013

Ngalamco. (2018). Kawasan Kayutangan, Salah satu kawasan bersejarah di Malang, (online) https://www.facebook.com/HARRISHotelMal ang/posts/362398310512008, diakses 8 Agustus 2018

Permana,Rizky, Wahyu. Kayutangan, Jalan Legendaris Malang yang Kini Tergilas Zaman. (online) Merdeka.com, diakses, 8 November 2016

Kisah Sejarah Kota Malang Yang Tak banyak Terungkap. (online) http://pattiromalang.blogspot.co.id, diakses April 2018

Ririh, N, (2011). Melirik Arsitektur Eklektik. Kompas (online), https://id.scribd.com/doc/134918228/arsitektur -eklektik. Diaksed 25 Desember 2012

Setyawan. (2010). Media Seni Rupa. (Online) senirupanusantara.blogspot.com/2010/08/media-senirupa.html 